\title{
Spatial distribution, environmental risk and source of heavy metals in street dust from an industrial city in semi-arid area of China
}

\author{
Xiufeng Han ${ }^{1,2}$, Xinwei Lu* \\ ${ }^{1}$ Shaanxi Normal University, P.R. China \\ School of Tourism and Environment \\ ${ }^{2}$ Science and Technology University of Inner Mongolia, P.R. China \\ College of Resources and Environment, Baotou Normal College \\ *Corresponding author's e-mail: luxinwei@snnu.edu.cn
}

Keywords: heavy metals, spatial distribution, source, risk assessment, industrial city, dust.

\begin{abstract}
Environmental risks associated with $\mathrm{Co}, \mathrm{Cr}, \mathrm{Cu}, \mathrm{Mn}, \mathrm{Ni}, \mathrm{Pb}, \mathrm{V}$ and $\mathrm{Zn}$ in street dust collected from Baotou, a medium-sized industrial city in a semi-arid area of northwest China, were assessed by using enrichment factor and the potential ecological index. Their spatial distributions and sources in the dust were analyzed on the basis of geostatistical methods and multivariate statistical analysis, respectively. The results indicate that street dust in Baotou has elevated heavy metal concentrations, especially of $\mathrm{Co}, \mathrm{Cr}, \mathrm{Cu}, \mathrm{Pb}$ and $\mathrm{Zn}$. Co in the dust was significantly enriched. $\mathrm{Cr}$ and $\mathrm{Pb}$ were from moderate to significant enrichment. $\mathrm{Cu}$ and $\mathrm{Zn}$ were from minimal to moderate enrichment, whereas $\mathrm{Mn}, \mathrm{Ni}$ and $\mathrm{V}$ in the dust were from deficient to minimal enrichment. The ecological risk levels of $\mathrm{Co}$ and $\mathrm{Pb}$ in the dust were moderate to considerable and low to moderate, respectively, whereas those of other heavy metals studied in the dust presented low ecological risk. Different distribution patterns were found among the analyzed heavy metals. Three main sources of these heavy metals were identified. $\mathrm{Cr}, \mathrm{Mn}, \mathrm{Ni}$ and $\mathrm{V}$ originated from nature and industrial activities. $\mathrm{Cu}, \mathrm{Pb}$ and $\mathrm{Zn}$ derived mainly from traffic sources, and $\mathrm{Co}$ was mainly from construction sources.
\end{abstract}

\section{Introduction}

Environmental deterioration and contamination have become serious in urban areas due to rapid, continuous and unorganized industrialization and urbanization (Kumar 2013, Holnicki et al. 2017). Among urban environmental issues and types of contamination, atmospheric pollution is one of the major environmental issues. Particulate matter, originating from natural sources and anthropogenic emissions, is the primary atmospheric pollutant in addition to sulfur dioxide $\left(\mathrm{SO}_{2}\right)$ and nitrogen oxides $\left(\mathrm{NO}_{\mathrm{x}}\right.$ ) (Lu et al. 2010, Holnicki et al. 2017). Atmospheric particulates can be deposited on the Earth's surface, forming dust. Dust can be re-suspended into the atmosphere by wind, affecting the atmospheric environment quality and human health (Khairy et al. 2011). As one type of urban environmental medium, dust is an important bond linking atmosphere, soil and water. It is a sink and source of contaminants in urban environments. Urban dust often contains high levels of toxic heavy metals and organic contaminants (Langer et al. 2010, Lu et al. 2010, Chłopek et al. 2016) owing to various anthropogenic sources such as industrial emissions, traffic emissions, coal and fuel combustion, waste disposal, municipal activities, construction, and residential heating (Thorpe and Harrison 2008, Lu et al. 2014). Due to their toxicity, persistence, bioaccumulation, and biomagnifications, heavy metals in dust pose a potential threat to ecological systems and human health (Shi et al. 2011). Heavy metals concentrated in dust can be easily transferred into the human body by inhalation, ingestion and dermal contact absorption (Glorennec et al. 2012). They accumulate in the tissues and internal organs of the human body (Zheng et al. 2010), affecting the central nervous system and acting as cofactors, initiators, or promoters of other diseases (Faiz et al. 2009). Therefore, research on heavy metal contamination in dust is essential to understanding the possible change of urban environmental quality caused by intensive anthropogenic activities.

Concentrations, distributions, source identification, contamination levels and risk assessment of heavy metals in street dust have been investigated internationally in recent decades (Charlesworth et al. 2003, Ahmed and Ishiga 2006, Faiz et al. 2009, Lu et al. 2010, Atiemo et al. 2011). Although most of the existing studies were carried out in developed countries or the megacities of developing countries (Banerjee 2003, Han et al. 2006, Shi et al. 2011, Nazzal et al. 2013, Tang et al. 2013), limited information is available on heavy metal contamination of street dust in rapidly industrializing and urbanizing medium and small cities ( $\mathrm{Lu}$ et al. 2014). Differences among cities, including population density and 
industrial activities, could have a large impact on the findings of individual studies (Lu et al. 2014). The environmental issues are even more serious in the medium and small industrial cities, compared with megacities, due to the neglect of environmental protection or the lack of pollution treatment technology ( $\mathrm{Lu}$ et al. 2014).

Source identification of heavy metals is a very complex problem. GIS spatial analysis may have strong applicability in the discrimination of local pollution. The element tracing technique is used to identify the source of a certain element. Multivariate statistical methods (correlation analysis, principal component analysis and cluster analysis) reflect the overall pollution of the whole study area, and the discrimination ability of the local pollution is limited. Therefore, the use of comprehensive methods for source identification of heavy metals is necessary. In this paper, we have combined multivariate statistical analysis with GIS spatial analysis, the change of time series and the characteristics of the surrounding environment to identify sources of heavy metals in street dust from Baotou city.

Baotou is a medium-sized industrial city in a semi-arid area of northwest China. Like other metropolises of China, Baotou city faces many environmental problems caused by its hostile environment, poor urban planning, and rapid development. Especially, since the implementation of the Chinese Great Western Development policy in the 1990s was carried out, the problems became serious. With large centralized anthropogenic activities, there is a need to evaluate the urban environmental quality. In our previous work, we reported heavy metal concentrations and a contamination assessment for different-sized particles of street dust from Baotou and found that $\mathrm{Cr}$, $\mathrm{Cu}, \mathrm{Mn}, \mathrm{Ni}, \mathrm{Pb}, \mathrm{V}$ and $\mathrm{Zn}$ were mainly accumulated in the $<50 \mu \mathrm{m}$ particles, whereas Co was primarily accumulated in 300-1000 $\mu \mathrm{m}$ dust particles, and $\mathrm{Ba}$ was mostly present in 100-300 $\mu \mathrm{m}$ particles (Han et al. 2016). To the best of our knowledge, the literature on the spatial distribution, the environmental risk and source identification of heavy metals in street dust from Baotou city is still non-existent. The objectives of the present study focus on determining the concentrations of heavy metals in the street dust of Baotou, mapping the spatial distribution of heavy metals through geostatistical analysis and GIS for the purpose of identifying the spatial patterns and possible hot spots of the concentrations of heavy metals, and identifying the potential sources or influencing factors of heavy metals in the dusts using correlation analysis, principal component analysis and cluster analysis. The contamination level and the potential ecological risk of heavy metals in the street dust were also assessed. The results could offer the basic information for regulators and engineering in environmental monitoring, protection and risk management.

\section{Materials and methods}

\section{Background of study area}

Baotou $\left(109^{\circ} 15^{\prime}-110^{\circ} 26^{\prime} \mathrm{E}, 40^{\circ} 15^{\prime}-42^{\circ} 43^{\prime} \mathrm{N}\right)$, the largest city in the Inner Mongolia autonomous region and an important industrial base of China, is located in the Tumochuan and Hetao Plains, with the Yellow River to the south and Mongolia to the north (Fig. 1). The climate of Baotou city is a typical semi-arid temperate continental monsoon climate, with an annual average temperature of $6.5^{\circ} \mathrm{C}$, an annual average precipitation of $240-400 \mathrm{~mm}$ and an annual evaporation capacity of 1940-2340 mm. The local soil type is mainly chestnut soil. The prevailing wind direction is northwest. The total area and urban area of Baotou are 27,768 and $1,051 \mathrm{~km}^{2}$, respectively, and its resident population was 2,692,900 in 2013. Baotou is the railway and highway transportation hub linking the north and northwest of China. The number of motor vehicles was 458,000 in 2013. Baotou has abundant iron, rare earth, niobium, titanium, manganese, gold, copper and other mineral resources. It is an important industrial base and rare earth industrial center of China. The main industries are the rare earth industry, iron and steel manufacturing, coal-fired power generation, aluminum smelting, dairy, heavy duty vehicles, metallurgy, and machinery manufacturing. The gross domestic product (GDP) of Baotou was 350,300 million RMB in 2013, with a 9.3 percent growth rate, and the industrial output value accounted for $\sim 52$ percent of the GDP. Aluminum, iron and steel, trace earth elements, electric power and equipment manufacturing account for $\sim 50$ percent of the industrial output.

\section{Sampling and analytical procedures}

A total of 83 street dust sampling sites were selected in the Baotou urban area (Fig. 1). At every sampling site, a dust composite sample of 300-500 g composed of 5-8 sub-dust samples was collected by sweeping using a clean plastic brush and dustpan during the cold and dry season in October 2012. The actual latitude and longitude coordinate of each sampling site was recorded by a global positioning system (GPS). All dust samples were stored in self-sealed polyethylene bags, labeled, and transported to the laboratory. After being air-dried at room temperature for two weeks, all samples were sieved through a $1.0 \mathrm{~mm}$ nylon mesh to remove large particles such as tree leaves, refuse and small stones before halving. One half was stored prior to analysis of physiochemical characteristics. Approximately $50 \mathrm{~g}$ of each sample was separated by halving, ground with an agate mortar and pestle, and then carefully homogenized and sieved through a $75 \mu$ m nylon mesh (Lu et al. 2010). To avoid potential cross-contamination of the samples, all handling procedures were carried out without contact with metals.

To measure metal concentrations, $4.0 \mathrm{~g}$ of milled dust samples and $2.0 \mathrm{~g}$ of boric acid were weighed out, placed in the mold (JJW-60, Changchun machine factory production) and pressed into a $32 \mathrm{~mm}$ diameter pellet under $30 \mathrm{t}$ of pressure ( $\mathrm{Lu}$ et al. 2010). Then, the concentrations of $\mathrm{Co}, \mathrm{Cr}, \mathrm{Cu}, \mathrm{Mn}, \mathrm{Ni}, \mathrm{Pb}, \mathrm{V}$ and $\mathrm{Zn}$ in the street dust samples were measured by wavelength dispersive X-ray fluorescence spectrometry (XRF, PANalytical PW-2403 apparatus), with a detection limit of $0.1 \mathrm{mg} \mathrm{kg}^{-1}$ for trace metals (Zhang et al. 2015). Standard samples (GSD12, GSS10) and $15 \%$ repeat samples were used for quality control in the experiment. The precision, calculated as the relative standard deviation of duplicate samples, was routinely $3-5 \%$. The analyzed accuracy, calculated from the relative error of the standard reference materials, was less than $5 \%$.

\section{Environmental risk assessment of heavy metals in street dust}

A number of different calculation methods have been applied to quantify the degree of heavy metal pollution or enrichment of heavy metals in street dust (Shi and Wang 2013). Examples of these methods include the enrichment factor, the potential 


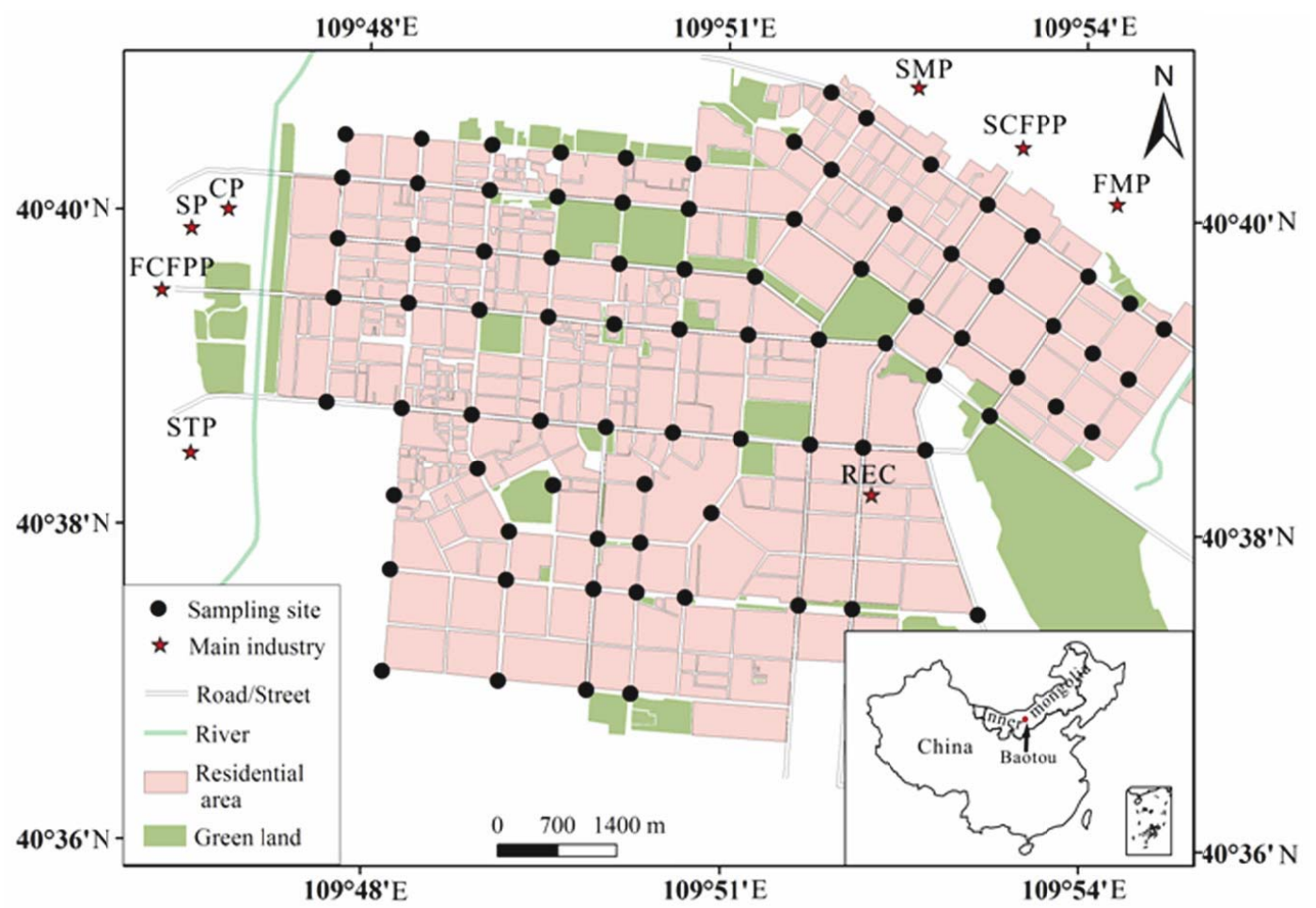

Fig. 1. Study area and sampling sites in Baotou, China. CP: cement plant; SP: steel plant; FCFPP: first coal-fired power plant; STP: steel tube plant; SMP: second machinery plant; SCFPP: second coal-fired power plant; FMP: first machinery plant; REC: Rare earth company

ecological risk index, the geo-accumulation index, the Nemerow pollution index, and the pollution index. Each method has its own advantages and disadvantages. The pollution index can provide a quantitative judgment for heavy metals; however, the method does not consider the variation of the background values caused by different contaminations and cannot reflect the ecological risk caused by heavy metals. The geo-accumulation index method can reveal the pollution level of heavy metals, but the method cannot reflect the toxic effects of heavy metals. The potential ecological risk index can partially overcome the shortcomings of the pollution index and the geo-accumulation index methods. The enrichment factor can also differentiate whether the metals originate from anthropogenic activities or from natural processes. Therefore, the enrichment factor can also assess the degree of anthropogenic influence (Han et al. 2006). Due to these characteristics, the enrichment factor and potential ecological risk index were used in the study to assess the accumulation level and degree of potential ecological risk of heavy metals in the dusts. The enrichment factor $(E F)$ of an element, an important parameter for evaluating the degree of impact of human activities on its enrichment, was calculated by (Buat-Menard and Chesselet 1979, Han et al. 2006, Turner and Simmonds 2006)

$$
E F=\left(C_{i} / C_{r e f}\right)_{\text {sample }} /\left(C_{i} / C_{r e f}\right)_{\text {background }}
$$

where $C_{i}$ is the concentration of heavy metal $i$, and $C_{r e f}$ is the concentration of the reference element for normalization. In the $E F$ calculation, the elements with low variability of occurrence, such as Al, Fe, Ti, Si, Sr and K, (Han et al. 2006, Turner and Simmonds 2006, Lu et al. 2010), can often be used as reference elements. $E F$ analysis can assist in differentiating anthropogenic sources from natural sources. A value of $E F$ close to 1 indicates a natural origin, where values $>10$ are considered to originate mainly from an anthropogenic source (Han et al. 2006; Turner and Simmonds 2006). EF can also assist in determining the degree of metal enrichment and contamination. $E F \leq 2$ means deficiency to minimal enrichment, $2<E F \leq 5$ means moderate enrichment, $5<E F \leq 20$ indicates significant enrichment, $20<$ $E F \leq 40$ signifies very high enrichment, and $40<E F$ means extremely high enrichment (Han et al. 2006).

The potential ecological risk index $(R I)$ of heavy metals was defined as (Håkanson 1980)

$$
R I=\sum_{i=1}^{n} E_{i}=\sum_{i=1}^{n} T_{i} \times C_{f}^{i}=\sum_{i=1}^{n} T_{i} \times \frac{C_{s}^{i}}{C_{b}^{i}}
$$

where $R I$ is the potential ecological risk index of heavy metals in the analyzed sample, $E_{i}$ is the potential ecological risk factor of heavy metal $i$, and $T_{i}$ is the toxic-response factor of heavy metal $i$ as calculated by Håkanson (1980) and Xu et al. (2008), i.e., $\mathrm{Co}(5)=\mathrm{Pb}(5)=\mathrm{Cu}(5)=\mathrm{Ni}(5)>\mathrm{Cr}(2)=\mathrm{V}(2)>\mathrm{Zn}(1)$ $=\operatorname{Mn}(1) . C_{f}^{i}$, which is the pollution index of heavy metal $i$, is equal to the concentration of heavy metal $i$ in the sample $\left(C_{s}^{i}\right)$ divided by its background value $\left(C_{b}^{i}\right)$. In this work, $C_{b}^{i}$ is the background value of local soil (Wang et al. 2007). The evaluation index classification presented by Hakanson (1980) was based on eight pollutants $(\mathrm{Hg}, \mathrm{Cd}, \mathrm{As}, \mathrm{Pb}, \mathrm{Cu}, \mathrm{Cr}, \mathrm{Zn}$ and $\mathrm{PCB}$ ) in sediments, whereas the pollutants considered in this study are $\mathrm{Co}, \mathrm{Cr}, \mathrm{Cu}, \mathrm{Mn}, \mathrm{Ni}, \mathrm{Pb}, \mathrm{V}$ and $\mathrm{Zn}$. Thus, the original evaluation index classification was adjusted according to the number of pollutants and the ratio of the toxicity coefficient of each element. The degree of ecological risk was classified 
as low ecological risk $\left(E_{i}<15, R I<50\right)$, moderate ecological risk $\left(15 \leq E_{i}<30,50 \leq R I<100\right)$, considerable ecological risk $\left(30 \leq E_{i}<60,100 \leq R I<200\right)$, high ecological risk $\left(60 \leq E_{i}<\right.$ $120, R I \geq 200)$ and very high ecological risk $\left(E_{i} \geq 120\right)$ (Lu et al. 2014; Zhu et al. 2008; Zhao and Li, 2013).

\section{Multivariate statistical analysis}

Correlation analysis, principal component analysis and cluster analysis have been widely used in the source identification of heavy metals in sediment (Kartal and Tokalığlu 2006, Yalcin et al. 2010), soil (Lee et al. 2006) and dust (Han et al. 2006; $\mathrm{Lu}$ et al. 2010; Tang et al. 2013). Correlation analysis can reveal the inter-relationship between pairs of the studied heavy metals. Principal component analysis (PCA) is used to reduce a large number of variable parameters and to extract a small number of principal components (Lu et al. 2010, Nazzal et al. 2013). Cluster analysis (CA) can classify elements of different sources on the basis of the similarities of their chemical properties. These three methods are complementary. Cluster analysis is used to verify the results of principal component analysis, and principal component analysis can quantitatively explain the results of cluster analysis. Correlation analysis can also improve and support the results of cluster analysis or principal component analysis. In this work, Correlation analysis, PCA and CA were conducted using the commercial statistics software package SPSS version 19.0 for Windows (SPSS Inc., USA) to identify the relationships among heavy metals in the street dusts and their possible sources.

\section{Results and discussion}

\section{Heavy metal concentrations in street dust}

Statistics of heavy metal concentrations in the street dust of Baotou, as well as background values of local soil (Wang et al. 2007), are shown in Table 1 . Table 1 reveals that the concentrations of $\mathrm{Co}, \mathrm{Cr}$ and $\mathrm{Pb}$ in all of the dust samples, $\mathrm{V}, \mathrm{Cu}$ and $\mathrm{Zn}$ in $90 \%$ of the samples, and $\mathrm{Mn}$ in of the $50 \%$ samples are higher than their corresponding background values, whereas the concentrations of $\mathrm{Ni}$ in most samples $(95 \%)$ are lower than its background value in local soil. The measurement results indicate that the dusts of Baotou have elevated concentrations of heavy metals, especially $\mathrm{Co}, \mathrm{Cr}$, $\mathrm{Cu}, \mathrm{Pb}$ and $\mathrm{Zn}$, which are 4.0-10.7, 1.8-5.8, 0.9-4.0, 1.5-8.7 and $0.8-2.4$ times the background values of local soil (Wang et al. 2007), respectively. The mean concentrations of heavy metals in street dust from Baotou divided by the corresponding background value of local soil decrease in the order $\mathrm{Co}>\mathrm{Pb}>$ $\mathrm{Cr}>\mathrm{Zn}>\mathrm{Cu}>\mathrm{V} \approx \mathrm{Mn}>\mathrm{Ni}$. $\mathrm{Co}, \mathrm{Cr}, \mathrm{Cu}, \mathrm{Pb}$, and $\mathrm{Zn}$ in the dusts have larger coefficients of variation (CV $>20 \%$ ) than $\mathrm{Mn}, \mathrm{Ni}$, and $\mathrm{V}$, demonstrating that the concentration differences of $\mathrm{Co}$, $\mathrm{Cr}, \mathrm{Cu}, \mathrm{Pb}$, and $\mathrm{Zn}$ in all dust samples are appreciable and that the effects of anthropogenic activities on the concentrations of these metals are striking.

Kurtosis values of all analyzed heavy metals in the samples except for $\mathrm{Cr}$ and $\mathrm{Zn}$ are larger than zero, which indicates that the distributions of these metals are steeper than normal. The skewness values of $\mathrm{Cu}, \mathrm{Ni}$, and $\mathrm{Pb}$ are higher than unity, which demonstrates that these three elements positively skew towards lower concentrations ( $\mathrm{Lu}$ et al. 2010), as can be confirmed by the fact that their arithmetic mean concentrations are greater than their medium concentrations. As a result, the geometric means of $\mathrm{Cu}, \mathrm{Ni}$, and $\mathrm{Pb}$ provide more valid data than their arithmetic means (Lu et al. 2010).

The concentrations of heavy metals in Baotou street dust are compared with data reported for other cities in the world in Table 1. The mean concentrations of Co in Baotou street dust are appreciably higher than in other cities, whereas the mean concentrations of $\mathrm{Cu}, \mathrm{Pb}$ and $\mathrm{Zn}$ in street dust from Baotou are lower than those of other cities. The other trace metal concentrations in Baotou street dust are within the range of those of the compared cities. The street dust is a complex mixture of particulates and contaminants derived from an extensive range of urban and industrial sources and processes (Han et al. 2006). The deposition of atmospheric particulates is one type of important source of ground dust (Zhang et al. 2015). Dusts of different cities have various concentration levels of metals, which may be related to the local natural environment, economic development, urbanization level, industrial type, traffic, environmental protection and pollution control technologies, etc. Baotou is an important center of the iron and steel industry and the rare earth industry city in China. The higher concentrations of $\mathrm{Co}$ and $\mathrm{Cr}$ in Baotou are probably related to the urban construction and these two types of industrial activities. In contrast, the lower concentrations of other heavy metals in Baotou compared with Baoji and Tongchuan, particularly $\mathrm{Cu}, \mathrm{Pb}$, and $\mathrm{Zn}$, may be related to the heavy traffic in the other cities.

\section{Spatial distribution of heavy metals in street dust}

The spatial distributions of $\mathrm{Co}, \mathrm{Cr}, \mathrm{Cu}, \mathrm{Mn}, \mathrm{Ni}, \mathrm{Pb}, \mathrm{V}$ and $\mathrm{Zn}$ in the street dust of Baotou city were determined using the Kriging interpolation method with ArcGIS software, and the results are shown in Fig. 2. Fig. 2a shows that there are two high-value zones of Co concentration ( $>6$ times the background value) in the study area, i.e., the north high-value zone and the middle-south high-value zone. The north high-value zone of Co concentration is located in the vicinities of a machinery plant and residential areas, whereas the middle-south high-value zone is situated near commercial areas and residential areas, with many construction sites and a building and decorative materials market. The spatial distribution characteristics of $\mathrm{Cr}$ concentrations in the dusts revealed that the west is higher than the east (Fig. 2b). The west high-value zone of $\mathrm{Cr}$ concentration is located in the vicinity of a steel plant, a coal-fired power plant, a machinery plant and a cement plant, and the sporadic hot-spots of $\mathrm{Cr}$ concentration are located near garages. As for the concentration of $\mathrm{Cu}$ in the dust, one hot-spot is found in the middle of the western study area (Fig. 2c). The street dust samples collected from the middle of the western study area, the area where the machinery plant, the building materials market and the commercial center are located (with heavy traffic), has higher $\mathrm{Cu}$ concentrations ( $>1.5$ times the background value). $\mathrm{Cu}$ concentrations in the dusts decrease radially from that hot-spot to the surroundings. The spatial distribution of Mn in the dusts (Fig. 2d) is similar to that of V (Fig. $2 \mathrm{~g}$ ), i.e., the concentrations of $\mathrm{Mn}$ and $\mathrm{V}$ decrease from west to east, and the dust samples collected from the southeastern part of the study area, the vicinity of a big Ecological Park, have lower $\mathrm{Mn}$ and $\mathrm{V}$ concentrations. The concentrations of $\mathrm{Ni}$ in most dust samples are close to or lower than its corresponding background value in local soil (24.5 $\mathrm{mg} \mathrm{kg}^{-1}$ ) (Wang et al. 2007). Moreover, the hot-spots of Ni concentration ( $>1.5$ times background value) 
Table 1. Descriptive statistics of heavy metals in street dust of Baotou and reference value as well as the reported data for other cities $\left(\mathrm{mg} \mathrm{kg}^{-1}\right)$

\begin{tabular}{|c|c|c|c|c|c|c|c|c|}
\hline Heavy metal & Co & $\mathrm{Cr}$ & $\mathrm{Cu}$ & $\mathrm{Mn}$ & $\mathrm{Ni}$ & $\mathrm{Pb}$ & V & $\mathrm{Zn}$ \\
\hline Min & 39.7 & 103.0 & 16.3 & 408.9 & 16.1 & 28.6 & 58.6 & 47.2 \\
\hline $5 \%$ & 41.8 & 124.9 & 19.2 & 439.9 & 17.7 & 31.4 & 63.1 & 57.4 \\
\hline $10 \%$ & 45.7 & 132.0 & 20.5 & 472.8 & 18.5 & 33.9 & 66.3 & 62.7 \\
\hline $25 \%$ & 51.2 & 146.7 & 22.8 & 502.4 & 19.7 & 42.7 & 68.8 & 73.2 \\
\hline Median & 59.4 & 176.6 & 27.9 & 553.5 & 21.5 & 58.8 & 73.7 & 90.3 \\
\hline Mean & 60.2 & 189.6 & 29.4 & 572.1 & 21.6 & 64.9 & 75.5 & 89.5 \\
\hline GM & 59.1 & 182.6 & 28.2 & 565.5 & 21.4 & 59.6 & 75.0 & 87.3 \\
\hline $75 \%$ & 64.6 & 225.8 & 32.5 & 627.0 & 22.7 & 81.0 & 80.6 & 106.1 \\
\hline $90 \%$ & 78.5 & 272.5 & 38.0 & 686.6 & 24.1 & 104.6 & 87.2 & 113.4 \\
\hline $95 \%$ & 82.6 & 291.3 & 46.6 & 717.7 & 24.9 & 120.5 & 90.2 & 122.0 \\
\hline Max & 105.8 & 327.7 & 77.1 & 894.3 & 43.5 & 162.7 & 103.2 & 136.4 \\
\hline SD & 12.3 & 53.8 & 9.8 & 89.2 & 3.2 & 28.4 & 8.7 & 19.6 \\
\hline CV(\%) & 20.4 & 28.4 & 33.4 & 15.6 & 14.9 & 43.8 & 11.5 & 21.9 \\
\hline Skewness & 0.9 & 0.7 & 2.5 & 0.7 & 3.9 & 1.2 & 0.9 & 0.0 \\
\hline Kurtosis & 1.2 & -0.3 & 9.2 & 1.1 & 26.3 & 1.5 & 1.0 & -0.8 \\
\hline Reference value $^{a}$ & 9.93 & 56.4 & 19.17 & 508.6 & 24.5 & 18.76 & 65.5 & 55.68 \\
\hline Baojib & 15.9 & 126.7 & 123.2 & 804.2 & 48.8 & 433.2 & 88.9 & 715.3 \\
\hline Tongchuan $^{c}$ & 34.0 & 106.4 & 32.6 & 369.1 & 25.3 & 75.2 & 55.7 & 141.8 \\
\hline Xi'an $^{d}$ & & 167.28 & 94.98 & 687 & & 230.52 & & 421.46 \\
\hline Guangzhoue & 13.0 & 78.8 & 176 & 481 & 23.0 & 120 & 23.0 & 586 \\
\hline Ottawa $^{f}$ & 8.31 & 43.3 & 65.84 & 431.5 & 15.2 & 39.05 & 34.0 & 112.5 \\
\hline Madridg & 3 & 61 & 188 & 362 & 44 & 1927 & 17 & 467 \\
\hline Luanda $^{\text {h }}$ & 2.9 & 26 & 42 & 258 & 10 & 351 & 20 & 317 \\
\hline Avilési & 7.03 & 41.6 & 183 & 1661 & 27.5 & 514 & 28.1 & 4892 \\
\hline
\end{tabular}

GM: geometric mean, SD: standard deviation, CV: coefficient of variation.

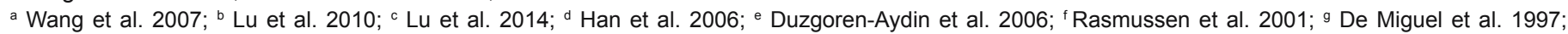

h Ferreira-Baptista and De Miguel 2005; ' Ordóñez et al. 2003

are very limited and mainly distributed in the center of the study area (Fig. 2e): the neighborhoods of the steel plant, the coal-fired power plant, the machinery plant and the garages.

With regard to the spatial distribution of $\mathrm{Pb}$, one hot-spot was found in the center of the study area, which is the commercial center of Baotou city and has the busiest traffic. The concentrations of $\mathrm{Pb}$ in street dusts decline gradually from the center hot-spot to the surroundings (Fig. 2f). The concentration of $\mathrm{Zn}$ in the dusts has a similar spatial distribution to that of $\mathrm{Cu}$, i.e., the dust samples collected from the west industrial area and the commercial area with heavy traffic have higher $\mathrm{Zn}$ concentrations, whereas the dust samples from the southeastern part of the study area, which is the largest park in Baotou city, have lower Zn concentrations (Fig. 2h). The spatial distribution characteristics of all analyzed heavy metals in the street dust of Baotou may be related to their sources and the influence of anthropogenic activities.

\section{Contamination and environmental risk of heavy metals in street dust}

Enrichment factors $(E F \mathrm{~s})$ of all analyzed metals were calculated for each dust sample relative to the background value of the local soil. In this study, $\mathrm{Al}$ is used as a reference element. The box-plots of $E F$ for metals in street dust from Baotou city are provided in Fig. 3. The order of mean $E F$ values is Co (6.8) $>$ $\mathrm{Cr}(3.8)>\mathrm{Pb}(3.5)>\mathrm{Zn}(1.8)>\mathrm{Cu}(1.7)>\mathrm{Mn}(1.3)=\mathrm{V}(1.3)$ $>\mathrm{Ni}(1.0)$. The mean $E F$ values of $\mathrm{Co}, \mathrm{Cr}$ and $\mathrm{Pb}$ were $>2$, indicating that the street dusts were contaminated by these metals. In particular, the maximum $E F$ values of $\mathrm{Co}$ and $\mathrm{Pb}$ were higher or close to 10 , showing that the sources of Co and $\mathrm{Pb}$ in the dust were related to human activities. The $E F$ values of $\mathrm{Mn}, \mathrm{Ni}$ and $\mathrm{V}$ in all dust samples were $<2$, showing deficiency to minimal enrichment. The $E F$ values of Co in $95 \%$ of the samples were between 5 and 20 , and those in $5 \%$ of the samples were between 2 and 5, indicating significant enrichment and moderate enrichment, respectively. The mean $E F$ values of $\mathrm{Cr}(3.8)$ and $\mathrm{Pb}(3.5)$, as well as $84 \%$ of the $E F$ values of $\mathrm{Cr}$ and $69 \%$ of the $E F$ values of $\mathrm{Pb}$, were between 2 and 5, indicating moderate enrichment, whereas $16 \%$ of the $E F$ values of $\mathrm{Cr}$ and $23 \%$ of the $E F$ values of $\mathrm{Pb}$ were in the 5-20 range, demonstrating significant enrichment. The mean $E F$ values of $\mathrm{Cu}(1.7)$ and $\mathrm{Zn}(1.8)$, as well as $83 \%$ of the $E F$ values of $\mathrm{Cu}$ and $67 \%$ of the $E F$ values of $\mathrm{Zn}$ were $<2$, revealing deficiency in minimal enrichment, whereas $17 \%$ of 

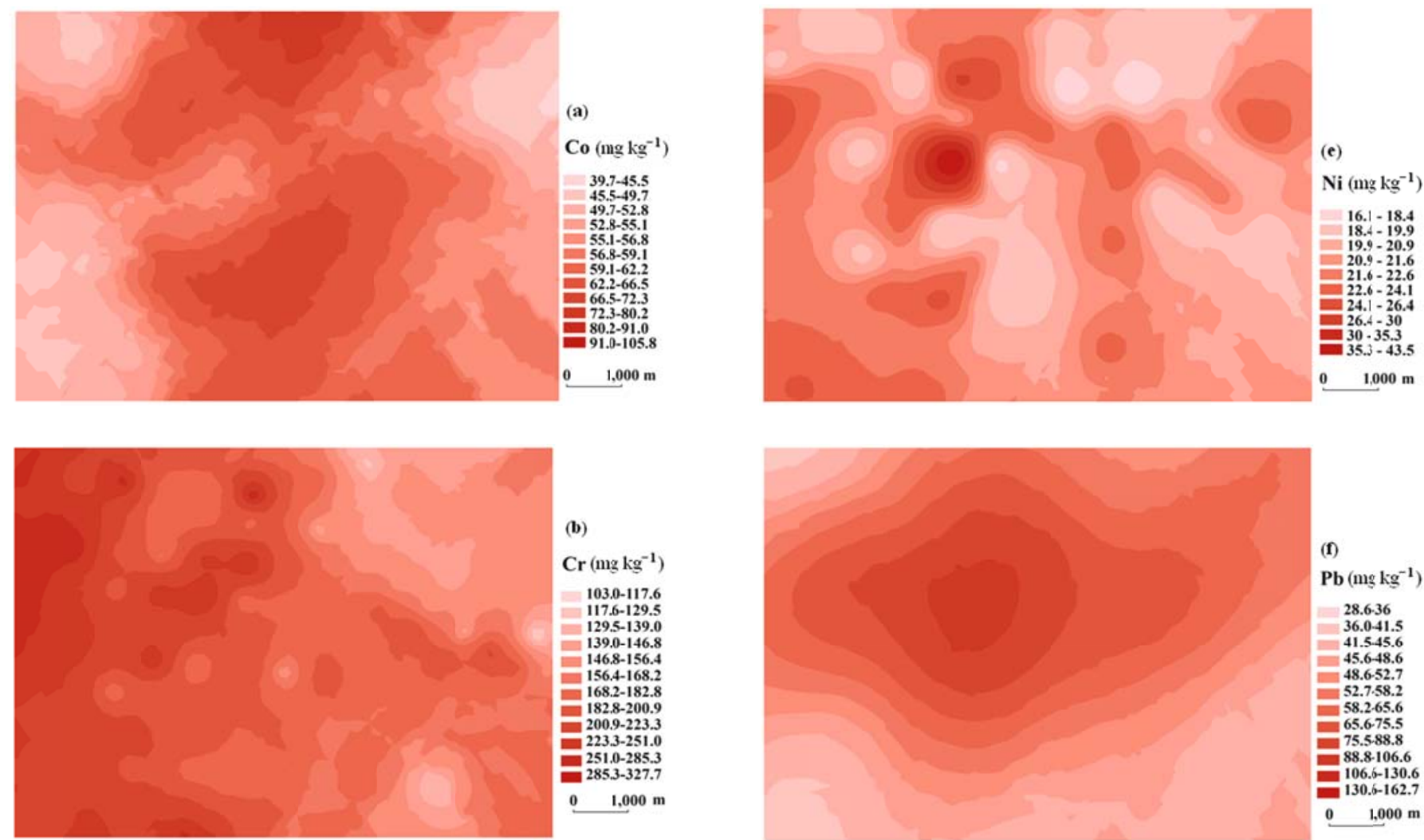

(b)
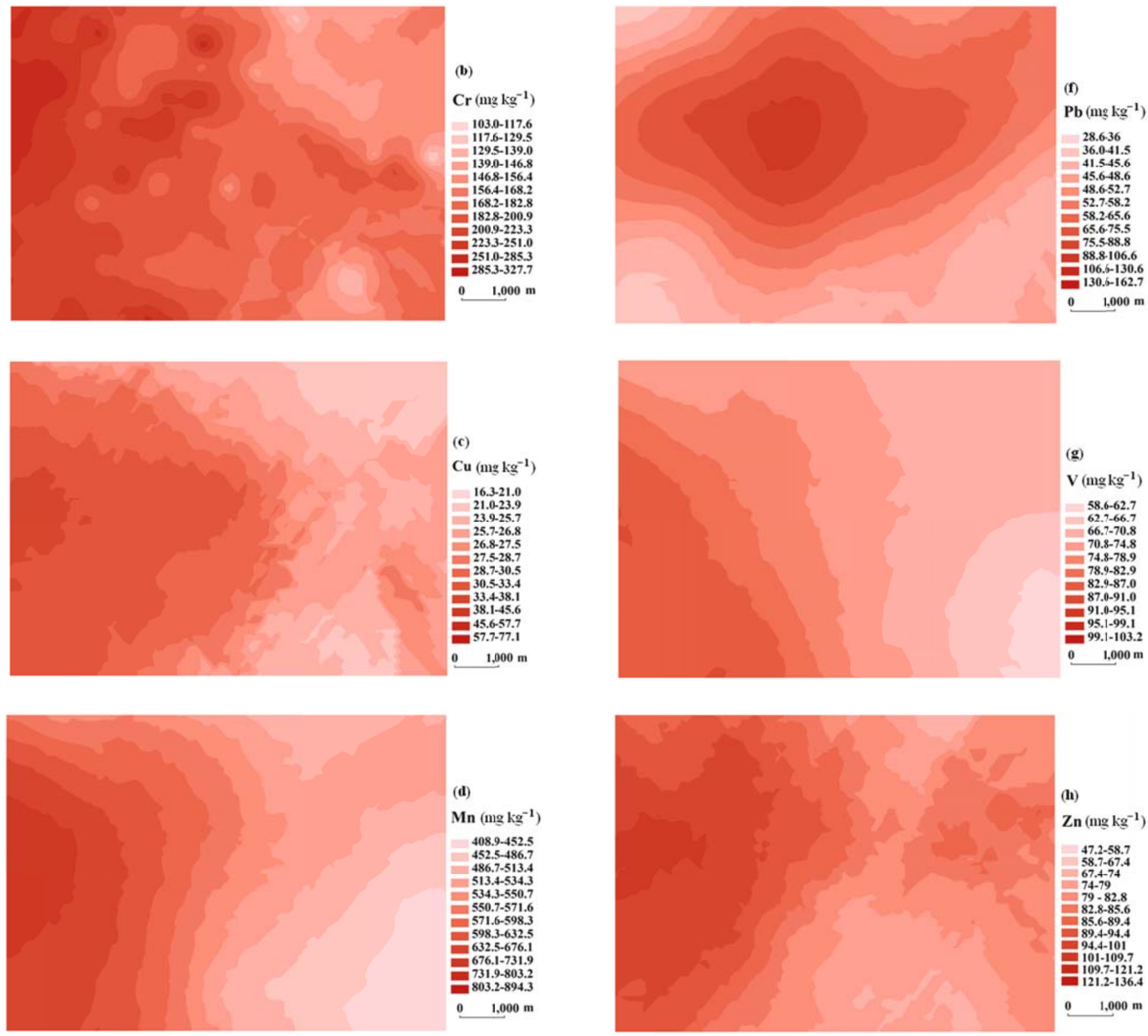

Fig. 2. Spatial distribution of heavy metal concentration in street dust of Baotou

the $E F$ values of $\mathrm{Cu}$ and $33 \%$ of the $E F$ values of $\mathrm{Zn}$ were in the range of $2-5$, indicating moderate enrichment.

The $E_{i}$ values of all analyzed metals in street dust collected from Baotou are summarized in Fig. 4. The mean $E_{i}$ value decreases in the order $\mathrm{Co}(30.3)>\mathrm{Pb}(17.3)>\mathrm{Cu}(7.7)>\mathrm{Cr}$ (6.7) $>\mathrm{Ni}(4.4)>\mathrm{V}(2.3)>\mathrm{Zn}(1.6)>\mathrm{Mn}$ (1.1), which is different from their order of enrichment factors. The reason for this phenomenon is due to the difference in their toxic-response factors. The $E_{i}$ values of $\mathrm{Cr}, \mathrm{Mn}, \mathrm{Ni}, \mathrm{V}$ and $\mathrm{Zn}$ in all of the dust samples and those of $\mathrm{Cu}$ in $96 \%$ of the samples were $<15$, indicating low ecological risk. The $E_{i}$ values of $\mathrm{Pb}$ in $43 \%$ of the samples were $<15$, those in $49 \%$ of the samples 

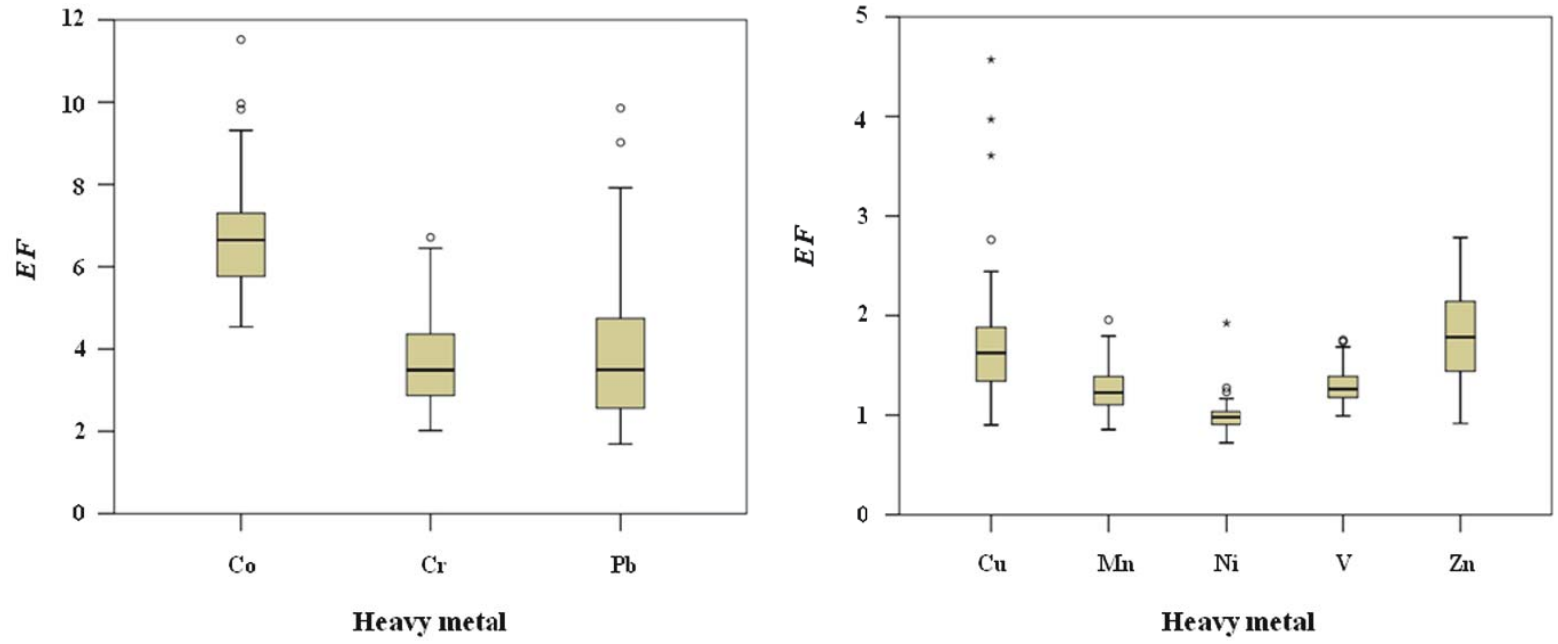

Fig. 3. Box-plot of EF for heavy metals in street dust of Baotou

were between 15 and 30 , and those in $8 \%$ of the samples were between 30 and 60 , indicating that $\mathrm{Pb}$ in the dusts was mainly associated with low to moderate ecological risk, whereas some samples presented considerable ecological risk. The $E$. values of $\mathrm{Co}$ in $51 \%$ of the samples were between 15 and 30 , and those in $49 \%$ of the samples were between 30 and 60 , showing that $\mathrm{Co}$ in street dust of Baotou presented moderate to considerable ecological risk. The potential ecological risk index $(R I)$ of heavy metals in street dust of Baotou ranged from 49.7 to 101.1 with a mean of 71.5 , revealing that the comprehensive ecological risk of heavy metals in the dust was moderate, which was mainly due to the contributions of $\mathrm{Co}$ (42.4\%) and $\mathrm{Pb}(24.2 \%)$.

\section{Source identification of heavy metals in street dust}

Sources of heavy metals in street dust collected from Baotou were identified using multivariate statistical analysis methods by combined use of their concentrations, spatial distributions and enrichment levels. Principle component analysis (PCA) results show that there are three eigenvalues $>1$ and that these three principle components explain $72.47 \%$ of the total variance (Table 2). The first principle component explains $33.38 \%$ of the total variance, and it is loaded heavily on $\mathrm{Cr}$, $\mathrm{Mn}, \mathrm{Ni}$ and $\mathrm{V}$. They are significantly positively correlated with each other at $P<0.01$ (Table 3 ) and are classified into one cluster by the cluster analysis (Fig. 5). These results indicate that $\mathrm{Cr}, \mathrm{Mn}, \mathrm{Ni}$ and $\mathrm{V}$ have the same sources in the dusts. $\mathrm{Cr}$, $\mathrm{Mn}, \mathrm{Ni}$ and $\mathrm{V}$ are extensively used to produce stainless steel and alloys (Yeung et al. 2003), which can be confirmed by the spatial distributions of $\mathrm{Cr}, \mathrm{Mn}, \mathrm{Ni}$ and $\mathrm{V}$ in the dusts. The high-value zones of $\mathrm{Cr}, \mathrm{Mn}, \mathrm{Ni}$ and $\mathrm{V}$ in street dust from Baotou are located in the neighborhoods of the steel plant, the coal-fired power plant and the machinery plant. $\mathrm{Cr}$ in all dust samples presents elevated concentrations compared to the local soil and its enrichment factors are higher $(E F=2.0-6.7)$, showing $\mathrm{Cr}$ in the dusts mainly originated from anthropogenic sources, i.e. industrial sources. $\mathrm{Mn}, \mathrm{Ni}$ and $\mathrm{V}$ in the dusts are deficiency to minimal enrichment, indicating that they mainly came from natural sources, partly came from anthropogenic sources.

The second principle component is loaded primarily by $\mathrm{Cu}, \mathrm{Pb}$ and $\mathrm{Zn}$, accounting for $23.34 \%$ of the total variance
(Table 2). $\mathrm{Cu}, \mathrm{Pb}$ and $\mathrm{Zn}$ have significantly positive correlations in correlation analysis (Table 3 ) and are classified together in $\mathrm{CA}$ (Fig. 5). These results indicate that $\mathrm{Cu}, \mathrm{Pb}$ and $\mathrm{Zn}$ have similar sources in the street dust of Baotou. The concentrations of $\mathrm{Cu}, \mathrm{Pb}$ and $\mathrm{Zn}$ in the most dust samples are significantly higher than their background values in local soil. $\mathrm{Pb}$ presents moderate to significant enrichment in the dusts, and $\mathrm{Cu}$ and $\mathrm{Zn}$ display minimal to moderate enrichment in the dusts. These show that the sources of $\mathrm{Pb}, \mathrm{Cu}$ and $\mathrm{Zn}$ in the dusts are related to the local anthropogenic activities. $\mathrm{Cu}$ is a component of alloys used in mechanical parts due to its desirable qualities such as corrosive resistance and strength ( $\mathrm{Lu}$ et al. 2010). $\mathrm{Cu}$ is also present in brass automotive radiators due to its high corrosive resistance and high thermal conductivity (Yang et al. 2011), and it is often used in car lubricants (Lu et al. 2010). Zinc alloy and galvanized board are widely used in motor vehicles. Zinc compounds have also been employed extensively as antioxidants and as detergent/dispersant improvers for lubricating oils (De Miguel et al. 1997). Zn, added to tires during the vulcanizing process, comprises from $0.4 \%$ to $4.3 \%$ of the resulting tire tread (Lu et al. 2010). The wear and tear of vulcanized vehicle tires and corrosion of galvanized automobile parts are the main sources of $\mathrm{Zn}$ in the urban environment (Han et al. 2006; Lu et al. 2010). Deterioration of the mechanical parts in vehicles over time results in $\mathrm{Cu}$ and $\mathrm{Zn}$ being emitted to the surrounding environment (Li et al. 2004). Oxidation of lubricating oils upon exposure to air at high temperature results in the formation of organic compounds that are corrosive to metals ( $\mathrm{Lu}$ et al. 2010). $\mathrm{Cu}$ and $\mathrm{Zn}$ can be released to the urban environment as a result of wear of automobile oil pumps or corrosion of metal parts that come into contact with the oil (Lu et al. 2010). The spatial distribution patterns of $\mathrm{Cu}, \mathrm{Pb}$ and $\mathrm{Zn}$ in the street dust of Baotou show that the higher-value zones for $\mathrm{Cu}, \mathrm{Pb}$ and $\mathrm{Zn}$ are distributed in a similar manner, i.e., centered in the west-middle industrial area and commercial center, which have heavy traffic, suggesting that $\mathrm{Cu}, \mathrm{Pb}$ and $\mathrm{Zn}$ in the street dust of Baotou mainly originated from vehicular traffic.

The third principle component is dominated by Co, accounting for $15.75 \%$ of the total variance (Table 2 ). The coefficient of variation of $\mathrm{Co}$ is relatively large, and its concentrations in the street dusts are clearly higher than its 

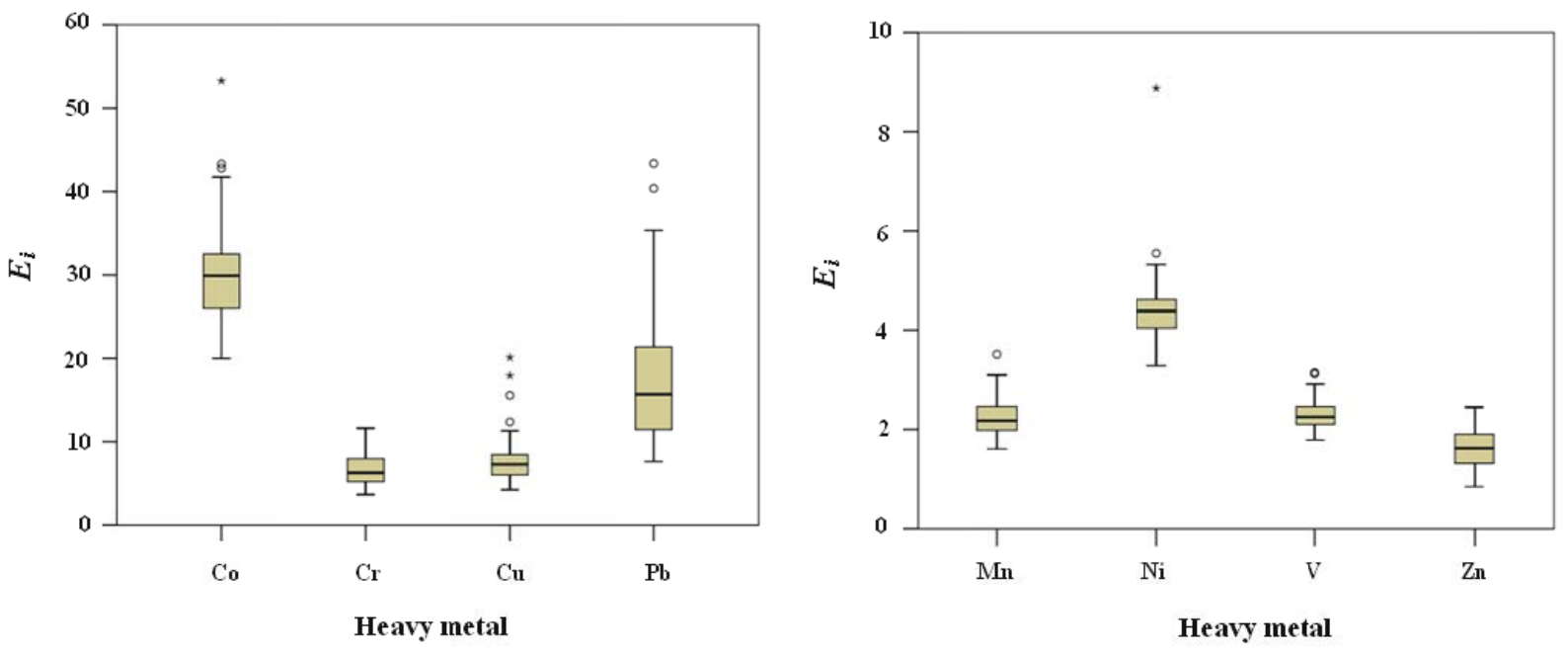

Fig. 4. Box-plot of EF for heavy metals in street dust of Baotou

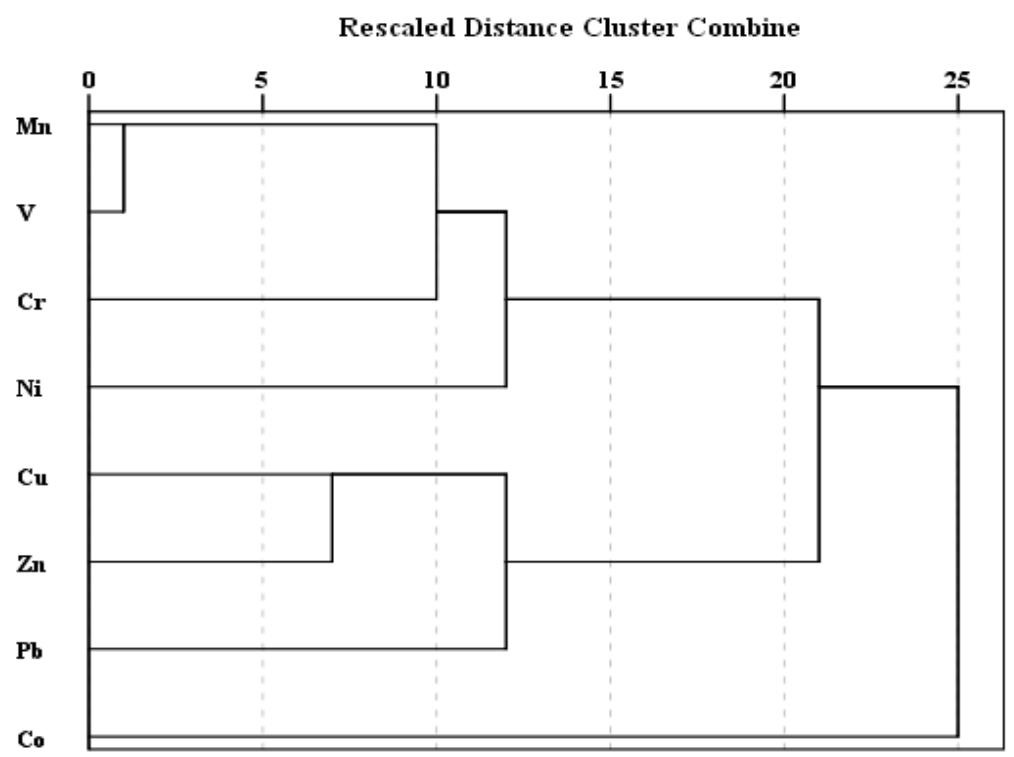

Fig. 5. Dendrogram results of cluster analysis based on Ward's method of hierarchical cluster analysis for eight elements

Table 2. Rotated component matrix for data of urban dusts

\begin{tabular}{|l|c|c|c|c|}
\hline Element & \multicolumn{3}{|c|}{ Component } & Communalities \\
\hline & 1 & 2 & 3 & 0.962 \\
\hline $\mathrm{Co}$ & 0.027 & 0.042 & 0.078 & 0.928 \\
\hline $\mathrm{Cr}$ & 0.798 & -0.067 & 0.022 & 0.647 \\
\hline $\mathrm{Cu}$ & 0.341 & 0.665 & -0.236 & 0.559 \\
\hline $\mathrm{Mn}$ & 0.813 & 0.345 & 0.100 & 0.836 \\
\hline $\mathrm{Ni}$ & 0.621 & 0.260 & 0.092 & 0.463 \\
\hline $\mathrm{Pb}$ & -0.020 & 0.825 & -0.128 & 0.817 \\
\hline $\mathrm{V}$ & 0.876 & 0.183 & -0.487 & 0.859 \\
\hline $\mathrm{Zn}$ & 0.322 & 0.720 & 1.26 & 15.75 \\
\hline Eigenvalue & 2.67 & 1.87 & 72.47 & \\
\hline$\%$ of variance explained & 33.38 & 23.34 & 56.72 & \\
\hline \% of cumulative & 33.38 & & & \\
\hline
\end{tabular}

Rotation method: varimax with Kaiser normalization. Extraction method: principal component analysis, after 4 times of iteration convergence in rotation. PCA loadings $>0.5$ are shown in bold. 


\begin{tabular}{|c|c|c|c|c|c|c|c|c|}
\hline & $\mathrm{Co}$ & $\mathrm{Cr}$ & $\mathrm{Cu}$ & $\mathrm{Mn}$ & $\mathrm{Ni}$ & $\mathrm{Pb}$ & $\mathrm{V}$ & $\mathrm{Zn}$ \\
\hline $\mathrm{Co}$ & & 0.907 & 0.648 & 0.219 & 0.591 & 0.653 & 0.663 & 0.001 \\
\hline $\mathrm{Cr}$ & 0.013 & & 0.024 & 0.000 & 0.000 & 0.507 & 0.000 & 0.163 \\
\hline $\mathrm{Cu}$ & 0.051 & $0.247^{*}$ & & 0.000 & 0.014 & 0.010 & 0.000 & 0.000 \\
\hline $\mathrm{Mn}$ & -0.136 & $0.523^{* *}$ & $0.414^{* *}$ & & 0.000 & 0.007 & 0.000 & 0.000 \\
\hline $\mathrm{Ni}$ & 0.060 & $0.374^{* *}$ & $0.269^{*}$ & $0.422^{* *}$ & & 0.124 & 0.000 & 0.000 \\
\hline $\mathrm{Pb}$ & 0.050 & 0.074 & $0.283^{* *}$ & $0.295^{* *}$ & 0.170 & & 0.238 & 0.000 \\
\hline $\mathrm{V}$ & -0.049 & $0.516^{* *}$ & $0.394^{* *}$ & $0.880^{* *}$ & $0.465^{* *}$ & 0.131 & & 0.000 \\
\hline $\mathrm{Zn}$ & $-0.365^{\star *}$ & 0.155 & $0.561^{* *}$ & $0.595^{\star *}$ & $0.394^{* *}$ & $0.434^{* *}$ & $0.430^{* *}$ & \\
\hline
\end{tabular}

The left lower part is correlation coefficient; the right upper part is significant level.

* Correlation is significant at the 0.05 level (two-tailed).

** Correlation is significant at the 0.01 level (two-tailed).

corresponding background value in local soil. Co presents significant enrichment in the dusts. These indicate that $\mathrm{Co}$ in the street dust is mainly governed by human activities. Co is not correlated with the other heavy metals considered, except for $\mathrm{Zn}$ (Table 3), and it is separated from other principal components in the PCA (Table 2) and clusters in the CA (Fig. 5), showing that Co has a different source than other heavy metals. Co is extensively used in alloys, coating materials, paints and pigments. These Co-containing materials are widely used in modern buildings due to their gloss, faultless color and visual impact. This is true for the reconstruction of the middle-south commercial area and the construction of the north residential area in Baotou city, which correspond precisely to the areas of high Co concentration in the dust. This suggests that Co in the street dust of Baotou predominantly originated from building construction or renovation, as well as weathering and corrosion of building materials.

\section{Conclusions}

Street dusts of Baotou have elevated $\mathrm{Co}, \mathrm{Cr}, \mathrm{Cu}, \mathrm{Pb}, \mathrm{V}$ and $\mathrm{Zn}$ concentrations compared to the background values of local soil. $\mathrm{Mn}, \mathrm{Ni}$ and $\mathrm{V}$ in the dusts exhibited deficiency to minimal enrichment. $\mathrm{Cu}$ and $\mathrm{Zn}$ exhibited minimal to moderate enrichment, whereas $\mathrm{Cr}$ and $\mathrm{Pb}$ exhibited moderate to significant enrichment, and Co exhibited significant enrichment in the dusts. The ecological risks of $\mathrm{Cr}, \mathrm{Mn}, \mathrm{Ni}$, $\mathrm{V}, \mathrm{Zn}$ and $\mathrm{Cu}$ in the dusts are low, whereas the ecological risk of $\mathrm{Pb}$ is low to moderate, and $\mathrm{Co}$ in the street dust of Baotou shows moderate to considerable ecological risk. The comprehensive ecological risks of all heavy metals analyzed in the dust are moderate. Different distribution patterns were found among the analyzed heavy metals. $\mathrm{Mn}$ and $\mathrm{V}, \mathrm{Cu}$ and $\mathrm{Zn}$ had similar distribution patterns. The middle of the western study area is the high-value area for most heavy metals. The zones of high Co concentration were located in the north and middle-south of the study area, where many construction sites are located. The dust samples collected from the industrial area and commercial area with heavy traffic have high $\mathrm{Cu}, \mathrm{Pb}$ and $\mathrm{Zn}$ concentration. Hot-spot areas of $\mathrm{Cr}, \mathrm{Mn}, \mathrm{Ni}$ and $\mathrm{V}$ are mainly associated with industrial activities. The source of $\mathrm{Cr}$, $\mathrm{Mn}, \mathrm{Ni}$ and $\mathrm{V}$ is a mixture of natural sources and industrial emissions of iron and steel plant and coal-fired power plan. $\mathrm{Cu}$,
$\mathrm{Pb}$ and $\mathrm{Zn}$ mainly originated from traffic emissions. Co was primarily derived from construction sources.

\section{Acknowledgements}

The research was supported by the National Natural Science Foundation of China through Grant 41271510, the Fundamental Research Funds for the Chinese Central Universities through Grants GK201601009, the Natural Science Foundation of Inner Mongolia 2014MS0402, the Inner Mongolia Autonomous Region Higher School Scientific Research Fund NJZC13230, and Baotou science and technology project 2014 S2004-3-1-27. We thank Guang Yang, Caifeng Zhao and Shigang Chao for their help with the experiments.

\section{References}

Ahmed, F. \& Ishiga, H. (2006). Trace metal concentrations in street dusts of Dhaka city, Bangladesh, Atmospheric Environment, 40, pp. 3835-3844.

Atiemo, M.S., Ofosu, G.F., Kuranchie-Mensah, H., Tutu, A.O., Palm, L. \& Blankson, S.A. (2011). Contamination assessment of heavy metals in road dust from selected roads in Accra, Ghana, Research Journal of Environmental Earth Science, 3, pp. 473-480.

Banerjee, A.D.K. (2003). Heavy metal levels and solid phase speciation in street dusts of Delhi India, Environmental Pollution, 123, pp. 95-105.

Buat-Menard, P. \& Chesselet, R. (1979). Variable influence of the atmospheric flux on the trace metal chemistry of oceanic suspended matter, Earth and Planet Science Letters, 42, pp. 399-411.

Charlesworth, S., Everett, M., McCarthy, R., Ordóñez, A. \& De Miguel, E. (2003). A comparative study on heavy metal concentration and distribution in deposited street dusts in a large and a small urban area: Birmingham and Covertry, West Midlands, UK, Environment International, 29, pp. 563-573.

Chłopek, Z., Suchocka, K., Dudek, M. \& Jakubowski, A. (2016). Hazards posed by polycyclic aromatic hydrocarbons contained in the dusts emitted from motor vehicle braking systems, Archives of Environmental Protection, 42(3), pp. 3-10.

De Miguel, E., Llamas, J. F., Chacón, E., Berg, T., Larssen, S., Røyset, O. \& Vadset, M. (1997). Origin and patterns of distribution of trace elements in street dust: unleaded petrol and urban lead, Atmospheric Environment, 31, pp. 2733-2740.

Duzgoren-Aydin, N.S., Wong, C.S.C., Aydin, A., Song, Z., You, M. \& Li, X.D. (2006). Heavy metal contamination and distribution in 
the urban environment of Guangzhou, SE China, Environmental Geochemistry and Health, 28, pp. 375-391.

Faiz, Y., Tufail, M., Javed, M.T., Chaudhry, M.M., \& Siddique, N. (2009). Road dust pollution of $\mathrm{Cd}, \mathrm{Cu}, \mathrm{Ni}, \mathrm{Pb}$ and $\mathrm{Zn}$ along Islamabad Expressway Pakistan, Microchemical Journal, 92, pp. 186-192.

Ferreira-Baptista, L. \& De Miguel, E. (2005). Geochemistry and risk assessment of street dust in Lunda, Angola: a tropical urban environment, Atmospheric Environment, 39, pp. 4501-4512.

Glorennec, P., Lucas, J.-P., Mandin, C. \& Bot, B.L. (2012). French children's exposure to metals via ingestion of indoor dust, outdoor playground dust and soil: Contamination data, Environment International, 45, pp. 129-134.

Han, X.F., Lu, X.W., Zhang, Q.H., Wuyuntana \& Hai, Q.S. (2016). Grain-size distribution and contamination characteristics of heavy metal in street dust of Baotou, China, Environmental Earth Sciences, doi: 10.1007/s12665-016-5316-Z.

Han, Y.M., Du, P.X., Cao, J.J. \& Posmentier, E.S. (2006). Multivariate analysis of heavy metal contamination in urban dusts of Xi'an, Central China, Science of the Total Environment, 355, pp. 176-186.

Håkanson, L. (1980). An ecological risk index for aquatic pollution control: a sedimentological approach, Water Research, 14, pp. 975-1001.

Holnicki, P., Kałuszko, A., Nahorski, Z., Stankiewicz, K. \& Trapp, W. (2017). Air quality modeling for Warsaw agglomeration, Archives of Environmental Protection, 43(1), pp. 48-64.

Kartal, Ş., Aydın, Z. \& Tokalıŏlu, Ş. (2006). Fractionation of metals in street sediment samples by using the BCR sequential extraction procedure and multivariate statistical elucidation of the data, Journal of Hazardous Materials, 132, pp. 80-89.

Khairy, M.A., Barakat, A.O., Mostafa, A.R. \& Wade, T.L. (2011). Multielement determination by flame atomic absorption of road dust samples in Delta Region Egypt, Microchemical Journal, 97 , pp. 234-242.

Kumar, S. (2013). Appraisal of heavy metal concentration in selected vegetables exposed to different degrees of pollution in Agra, India, Environmental Monitoring and Assessment, 185, pp. 2683-2690.

Langer, S., Weschler, C.J., Fischer, A., Bekö, G., Toftum, J. \& Clausen, G. (2010). Phythalate and PAH concentrations in dust collected form Danish homes and daycare centers, Atmospheric Environment, 44, pp. 2294-2301.

Lee, C.S. L., Li, X.D., Shi, W., Cheung, S.C.N. \& Thornton, I. (2006). Metal contamination in urban, suburban, and country park soils of Hong Kong: A study based on GIS and multivariate statistics, Science of the Total Environment, 356, pp. 45-61.

Li, X.D., Lee, S.L., Wong, S.C., Shi, W. \& Thornton, I. (2004). The study of metal contamination in urban soils of Hong Kong using a GIS-based approach, Environmental Pollution, 129, pp. 113-124.

Lu, X.W., Wang, L.J., Li, L.Y., Lei, K., Huang, L. \& Kang, D. (2010). Multivariate statistical analysis of heavy metals in street dust of Baoji, NW China, Journal of Hazardous Materials, 173, pp. 744-749.

Lu, X. W., Wu, X., Wang, Y.W., Chen, H., Gao, P.P. \& Fu, Y. (2014). Risk assessment of toxic metals in street dust from a medium-sized industrial city of China, Ecotoxicology and Environmental Safety, 106, pp. 154-163.

Nazzal, Y., Rosen, M.A. \& Al-Rawabdeh, A.M. (2013). Assessment of metal pollution in urban road dusts from selected highways of the Greater Toronto Area in Canada, Environmental Monitoring and Assessment, 185, pp. 1847-1858.

Ordóñez, A., Loredo, J., De Miguel, D. \& Charlesworth, S. (2003). Distribution of heavy metals in the street dusts and soils of an industrial city in Northern Spain, Archives of Environmental Contamination and Toxicology, 44, pp. 160-170.

Rasmussen, P.E., Subramanian, K.S. \& Jessiman, B.J. (2001). A multi-element profile of house dust in relation to exterior dust and soils in the city of Ottawa Canada, Science of the Total Environment, 267, pp. $125-140$.

Shi, G.T., Chen, Z.L., Bi, C.J., Wang, L., Teng, J.Y., Li, Y.S. \& Xu, S.Y. (2011). A comparative study of health risk of potentially toxic metals in urban and suburban road dust in the most populated city of China, Atmospheric Environment, 45, pp. 764-771.

Shi, X.M. \& Wang, J.H. (2013). Comparison of different methods for assessing heavy metal contamination in street dust of Xianyang city, NW China, Environmental Earth Sciences, 68, pp. 2409-2415.

Tang, R.L., Ma, K.M., Zhang, Y.X. \& Mao, Q.Z. (2013). The spatial characteristics and pollution levels of metals in urban street dust of Beijing, China, Applied Geochemistry, 35, pp. 88-98.

Thorpe, A. \& Harrison, R.M. (2008). Sources and properties of non-exhaust particulate matter from road traffic: a review, Science of the Total Environment, 400, pp. 270-282.

Turner, A. \& Simmonds, L. (2006). Elemental concentrations and metal bioaccessibility in UK household dust, Science of the Total Environment, 371, pp. 74-81.

Wang, X., Huang, Z., Su, M., Li, S., Wang, Z., Zhao, S. \& Zhang, Q. (2007). Characteristics of reference and background values of soils in Hetao area, Rock Mineral Analysis, 26, pp. 287-292. (in Chinese)

Xu, Z.Q., Ni, S.J., Tuo, X.G., \& Zhang, C.J. (2008). Calculation of heavy metals toxicity coefficient in the evaluation of potential ecological risk index, Environmental Science and Technology, 31, pp. 112-115. (in Chinese)

Yalcin, M. G., Tumuklu, A., Sonmez, M. \& Erdag, D.S. (2010). Application of multivariate statistical approach to identify heavy metal sources in bottom soil of the Seyhan River (Adana), Turkey, Environmental Monitoring and Assessment, 164, pp. 311-322.

Yang, Z., Lu, W., Long, Y., Bao, X. \& Yang, Q. (2011). Assessment of heavy metals contamination in urban topsoil from Changchun City, China, Journal of Geochemical Exploration, 108, pp. 27-38.

Yeung, Z.L.L., Kwok, R.C.K. \& Yu, K.N. (2003). Determination of multi-element profiles of street dust using energy dispersive X-ray fluorescence (EDXRF), Applied Radiation and Isotopes, 58, pp. 339-346.

Zhang, M.M., Lu, X.W, Chen, H., Gao, P.P. \& Fu, Y. (2015). Multi-element characterization and source idenfication of trace metal in road dust from an industrial city in sedmi-humid area of Northwest China, Journal of Radioanalytical and Nuclear Chemistry, 303, pp. 637-646.

Zhao, H.T. \& Li, X.Y. (2013). Risk assessment of metals in road-deposited sediment along an urban-rural gradient, Environmental Pollution, 174, pp. 297-304.

Zheng, N., Liu, J.S., Wang, Q.C. \& Liang, Z.Z. (2010). Health risk assessment of heavy metal exposure to street dust in the zinc smelting district, Northeast of China, Science of the Total Environment, 408, pp. 726-733.

Zhu, W., Bian, B. \& Li, L. (2008). Heavy metal contamination of road-deposited sediments in a medium size city of China, Environmental Monitoring and Assessment, 147, pp. 171-181. 